Check for updates

Cite this: RSC Adv., 2017, 7, 36112

\section{Acid-mediated sulfonylation of arylethynylene bromides with sodium arylsulfinates: synthesis of (E)-1,2-bis(arylsulfonyl)ethylenes and arylacetylenic sulfones $\uparrow$}

\author{
Chenshu Dai, Junqi Wang, Siqi Deng, Candong Zhou, Wenhe Zhang, Qiuhua Zhu (D) * \\ and Xiaodong Tang (D) *
}

Received 27th June 2017

Accepted 13th July 2017

DOI: $10.1039 / c 7 r a 07105 a$

rsc.li/rsc-advances

A solvent-dependent sulfonylation of arylethynylene bromides with sodium arylsulfinates has been developed. The (E)-1,2-bis(arylsulfonyl)ethylenes were formed in DMSO, while the arylacetylenic sulfones were obtained in toluene. Utilizing simple and readily available starting materials, the sulfonylation products were generated with good selectivities and yields without the need for a metal catalyst or oxidant.
Organosulfone compounds are of great importance in organic chemistry, due to their widely existing in natural products and drug molecules. ${ }^{1}$ Meanwhile, the sulfonyl group is also extensively used as versatile synthon for other organosulfur compounds synthesis. $^{2} \quad$ 1,2-Bis(arylsulfonyl)ethylenes are important organosulfone compounds and widely studied in synthetic applications. Firstly, they can act as $\pi$-deficient alkenes for cycloaddition reaction to synthesize cyclic compounds. ${ }^{3}$ Secondly, they play the role as leaving group in radical alkenylation reaction, in which various radicals add into the $\mathrm{C}-\mathrm{C}$ double bond and then eliminate a sulfonyl radical. ${ }^{4}$ Thirdly, in the presence of organocatalyst, they are able to undergo 1,2-sulfone rearrangement to form various other organosulfone compounds. ${ }^{5}$ Due to their importance, synthetic chemists have exploring their synthetic methods. However, the methods for synthesis of 1,2-bis(arylsulfonyl)ethylenes are still rarely. The most common method was the reaction of the 1,2dichloroethylene with phenylthiolate to give 1,2-bis(arylthio) ethylene which was followed by oxidation to furnish 1,2bis(arylsulfonyl)ethylenes (Scheme 1a) ${ }^{6 a}{ }^{6 a}$ While those multi-step synthesis was even impeded by limited symmetric 1,2-bis(arylsulfonyl)ethylenes formation. Reddy et al. reported a one-pot method, through the condensation of 1-arylsulfonyl-2,2dichloroethanes with sodium sulfinates in aqueous alcohol (Scheme 1b). ${ }^{6 \boldsymbol{b}}$ The $\beta$-((phenylsulfonyl)alkenyl)iodonium tetrafluoroborates were used as starting materials to form $(Z)-1,2-$

Guangdong Provincial Key Laboratory of New Drug Screening, School of Pharmaceutical Sciences, Southern Medical University, 1023 South Shatai Road, Baiyun District, Guangzhou 510515, P. R. China. E-mail: zhuqh@smu.edu.cn; tangxdong@smu.edu.cn

$\dagger$ Electronic supplementary information (ESI) available: Experimental section, characterization of all compounds, Fig. S1, copies of ${ }^{1} \mathrm{H}$ and ${ }^{13} \mathrm{C}$ NMR spectra for all target compounds. CCDC 1502249. For ESI and crystallographic data in CIF or other electronic format see DOI: $10.1039 / \mathrm{c} 7 \mathrm{ra} 07105 \mathrm{a}$ bis(arylsulfonyl)ethylenes by nucleophilic vinylic substitutions with sodium arylsulfinates. Except the multi-step preparation of vinyl-iodonium salts, stoichiometric amount of iodine benzene as a by-product placed this method in an unfavourable position (Scheme 1c). ${ }^{6 c}$ Kataoka et al. also developed a method for 1,2bis(phenylsulfonyl)ethylene via the reaction of alkynylselenonium salt with sodium benzenesulfinate (Scheme 1d). ${ }^{6 d-f}$ In the above methods, all have some obvious disadvantages such as multi-step processes, strong oxidants, unavailable starting materials, toxic by-products and so on. Hence, it is attractive and meaningful to develop a new method for synthesis of 1,2bis(arylsulfonyl)ethylenes in a direct, simple and green way.

Haloalkynes are easily available building blocks which can be prepared in quantitative yield in mol-scale on the bench top. Due to the electron-deficiency of haloalkyne, it usually used as an activated alkyne for addition reaction to give the sole regioselectivity. ${ }^{7}$ In recent years, some practical synthetic methods

\section{Previous work}

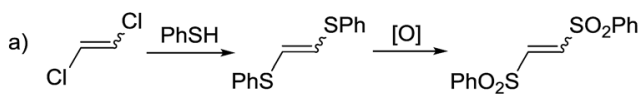

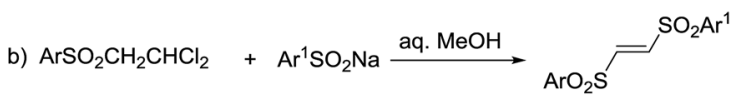

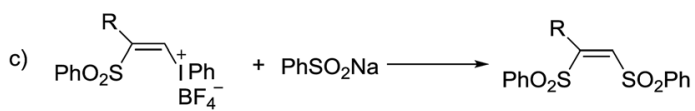

d) $\mathrm{Ph}=\underset{\mathrm{X}^{-}}{\stackrel{+}{\mathrm{S}}} \underset{\mathrm{HR}}{2} \stackrel{\mathrm{PhSO}_{2} \mathrm{Na}}{\mathrm{R}^{1} \mathrm{OH}} \underset{\mathrm{PhO}_{2} \mathrm{~S}}{\stackrel{\mathrm{Ph}}{\longrightarrow}=} \underset{\mathrm{SO}_{2} \mathrm{Ph}}{\mathrm{H}}$

This work

e) $\mathrm{Ar}^{1}=\mathrm{Br}+\mathrm{Ar}^{2} \mathrm{SO}_{2} \mathrm{Na} \stackrel{\mathrm{H}^{+}}{\longrightarrow} \underset{\mathrm{Ar}^{2} \mathrm{O}_{2} \mathrm{~S}}{\mathrm{Ar}^{1}}=\mathrm{SO}_{2} \mathrm{Ar}^{2}$

Scheme 1 Synthetic methods for 1,2-bis(arylsulfonyl)ethylenes. 
involving haloalkynes have been developed, including nucleophilic addition, ${ }^{8}$ cross-coupling reactions ${ }^{9}$ and cycloaddition reactions..$^{10}$ In comparison with sulfonyl chlorides, sodium sulfinates as mild sulfone moieties have many advantages, such as low toxicity, ready accessibility and stability. The sodium sulfinates are not only used as the simple nucleophilic reagents but also sulfonyl radicals to participate in the sulfonylation reaction. Recently, many endeavors have been made towards utilizing sodium sulfinates to synthesize organosulfone compounds. ${ }^{11}$ Based on the reaction development of haloalkynes and sodium sulfinates, we developed a direct synthesis of 1,2-bis(arylsulfonyl)ethylenes through tandem reaction between haloalkynes and sodium sulfinates under acidic conditions. Herein, we presented a acid-mediated synthesis of 1,2-bis(arylsulfonyl)ethylenes from bromoalkynes and sodium sulfinates (Scheme 1e).

We used the reaction between phenylethynyl bromide (1a) and sodium $p$-tolylsulfinate (2a) as a model to examine various reaction parameters and the results were summarized in Table 1. On the first trial, $1 \mathbf{a}$ and $\mathbf{2 a}$ (2.5 equiv.) were treated with $1 \mathrm{M} \mathrm{HCl}$ (1 equiv.) in DMSO as solvent at $60^{\circ} \mathrm{C}$ for $12 \mathrm{~h}$. To our delight, the target product 1,2-bis(tolylsulfonyl)phenylethene

Table 1 Optimization of the reaction conditions ${ }^{a}$

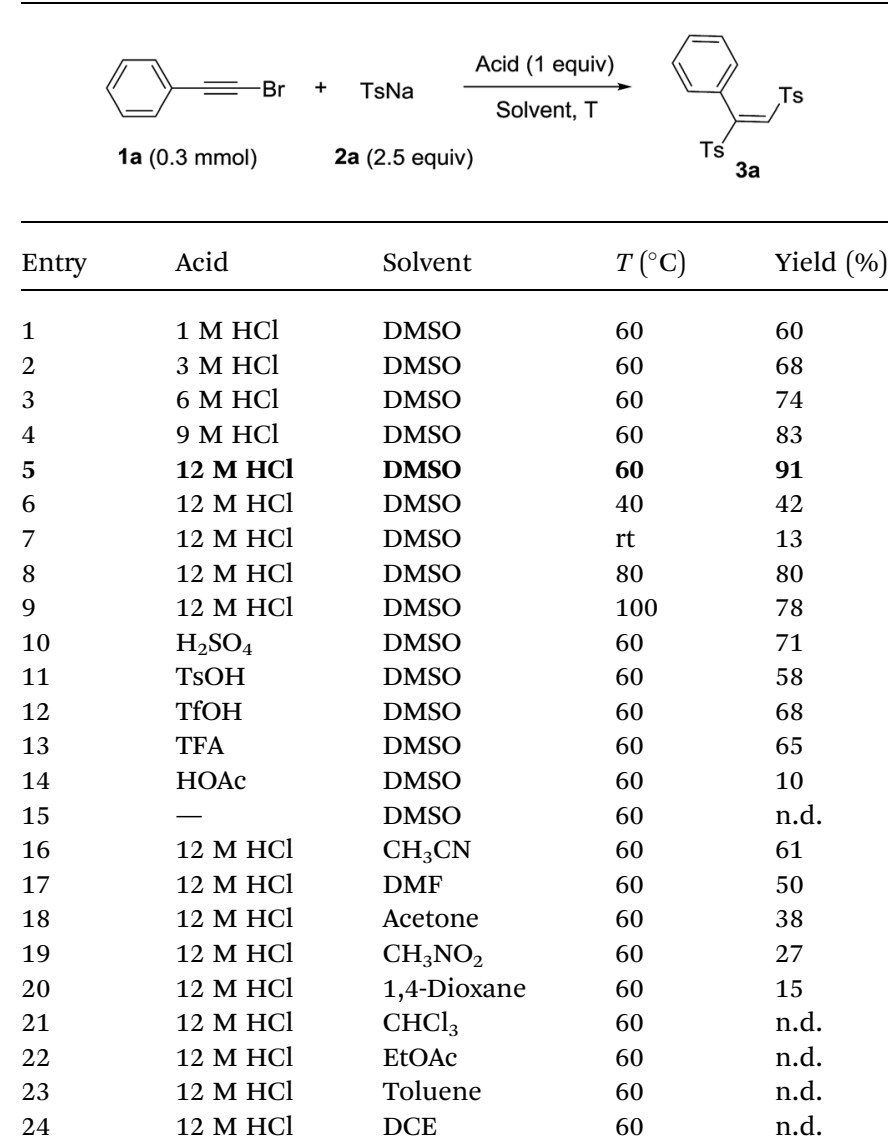

${ }^{a}$ Reaction were performed with $1 \mathrm{a}(0.3 \mathrm{mmol}), \mathbf{2 a}(0.75 \mathrm{mmol})$, acid $(0.3$ $\mathrm{mmol})$ in solvent $(3.0 \mathrm{~mL})$ for $12 \mathrm{~h}$. Isolated yield. n.d. = not determined. (3a) was obtained in $60 \%$ yield (entry 1). And the structure was confirmed by single-crystal X-ray analysis, in which the double bond is $E$-type configuration. ${ }^{12}$ Afterwards, we examined the concentration of hydrochloric acid and the results indicated that the yields increased with higher concentration $\mathrm{HCl}$ (entries $2-5$ ). The yield was raised up to $91 \%$ when $12 \mathrm{M} \mathrm{HCl}$ was used (entry 5). Next, the screening of reaction temperature showed that neither increasing nor decreasing the temperature led to a lower yield of product (entries 6-9). Other Brønsted acids such as $\mathrm{H}_{2} \mathrm{SO}_{4}$, TsOH, TfOH, TFA and HOAc were tested to give the product in decent yields (entries 10-14). Control experiment indicated that acid was essential for this transformation (entry 15). The screening of different solvents showed that the solvents played a critical role, the polar solvents were beneficial for the transformation (entries 16-24).

With the optimal reaction condition in hand, we next conducted a survey of various substrates to explore the scope of this transformation. As listed in Table 2, the reaction had a good substrate suitability and various substituted $(E)$-1,2-bis(arylsulfonyl)ethylenes were obtained in moderate to excellent yields. We firstly evaluated the scope of bromoalkynes. Various alkyl and halogen substitutions on benzene ring of

Table 2 Substrate scope for the synthesis of substituted $(E)-1,2-$ bis(arylsulfonyl) ethylenes ${ }^{a}$

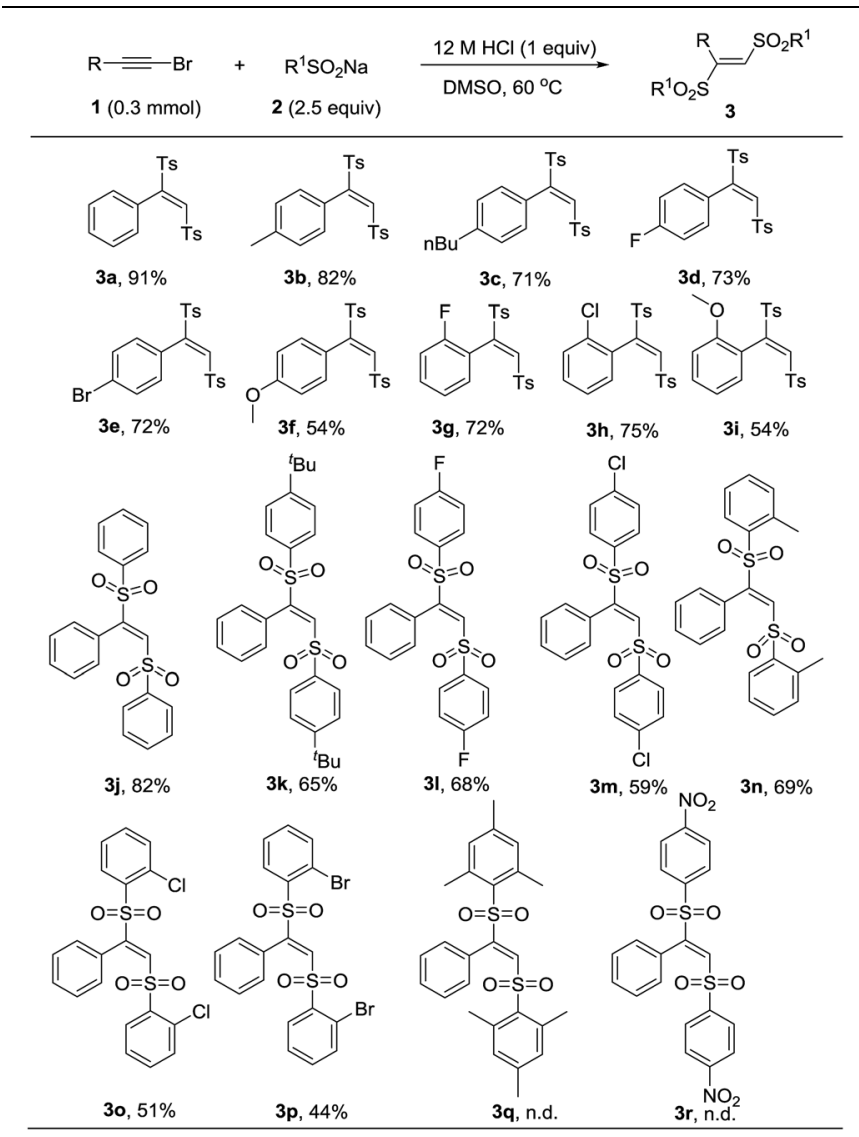

${ }^{a}$ Reactions were performed with $1(0.3 \mathrm{mmol}), 2(0.75 \mathrm{mmol}), 12 \mathrm{M} \mathrm{HCl}$ $(0.3 \mathrm{mmol})$, and DMSO $(3 \mathrm{~mL})$ at $60 \mathrm{C}$ for $12 \mathrm{~h}$. Yields was referred to isolated yields. 
phenylacetylene bromides were tolerated for this reaction. Strong electron-donating substitute such as methoxyl slightly decreased the yield of desired product (Table 2, 3f and 3i). For the substrate scope of sodium sulfinates, different parasubstituted sodium phenylsulfinates could be converted into the corresponding products in moderate to good yields (Table 2, 3j-3m). Even the steric hindered ortho-substituted sodium phenylsulfinates also worked efficiently to give the products in $44 \%$ to $69 \%$ yields (Table 2, 3n-3p). Unfortunately, more steric hindered mesitylenesulfinate and electron-deficient nitrobenzenesulfinate were failed to transform into the corresponding products (Table 2, 3q and 3r).

It was surprising that when 1a and $2 \mathrm{a}$ was treated with $12 \mathrm{M}$ $\mathrm{HCl}$ ( 1 equiv.) in toluene as solvent at $60{ }^{\circ} \mathrm{C}$ for $12 \mathrm{~h}$, the product acetylenic sulfone (4a) was formed in $48 \%$ yield..$^{13}$ Though some methods have been reported for the synthesis of acetylenic sulfones, they had some disadvantages such as unavailable starting materials and strong oxidant. ${ }^{14}$ Thus, we optimized the reaction conditions and the best reaction conditions were as followed: $1 \mathrm{a}(0.3 \mathrm{mmol}), 2 \mathrm{a}(0.75 \mathrm{mmol}), 1 \mathrm{M} \mathrm{HCl}(0.3 \mathrm{mmol})$, TBAI ( $20 \mathrm{~mol} \%$ ), in toluene $(3 \mathrm{~mL})$ at $60{ }^{\circ} \mathrm{C}$ for $12 \mathrm{~h}$ (see the ESI $\dagger$ for details). After establishing the optimized reaction conditions, the generality and limitations of various substrates were investigated. Firstly, sodium $p$-tolylsulfinate (2a) was treated with different substituted phenylacetylene bromides. Different para-substituted phenylacetylene bromides including alkyl group (Me, Et) and halides (F, Cl, Br) were well tolerated under the optimized condition to afford the products in $57 \%$ to $87 \%$ (Table 3, 4a-4f). Subsequently, the effect of ortho-substituents on the phenyl ring of phenylacetylene bromides were investigated. The product $\mathbf{4 g}$ and $\mathbf{4 h}$ were formed in $77 \%$ and $68 \%$ yields, respectively. Further investigating the scope of this transformation included various substitutions effect on sodium phenylsulfinates. Various sodium sulfinates could be proceeded

Table 3 Substrate scope for the synthesis of substituted acetylenic sulfone $^{a}$

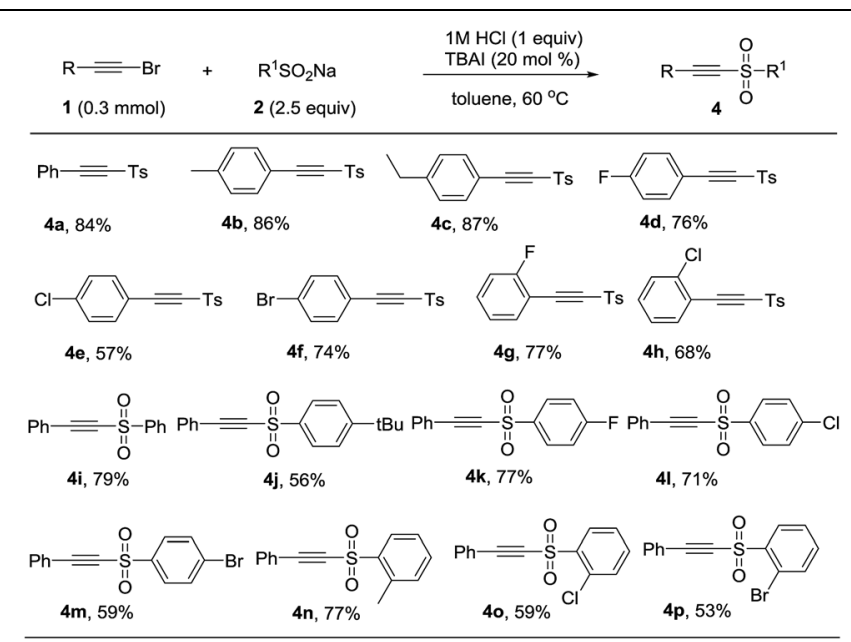

${ }^{a}$ Reaction conditions: 1 ( $\left.0.3 \mathrm{mmol}\right), 2(0.75 \mathrm{mmol}), 1 \mathrm{M} \mathrm{HCl}(0.3 \mathrm{mmol})$, TBAI $(20 \mathrm{~mol} \%)$, and toluene $(3 \mathrm{~mL})$ at $60^{\circ} \mathrm{C}$ for $12 \mathrm{~h}$. Yields was referred to isolated yields. smoothly and afforded the corresponding products in moderate to good yields (Table $3, \mathbf{4 i - 4 p ) . ~ I t ~ w a s ~ a ~ p i t y ~ t h a t ~ s o d i u m ~ a l k y l - ~}$ sulfinates was not appropriate for the transformation at this stage.

To gain more insight into the mechanism, the control experiments were carried out and shown in Scheme 2. When we utilized phenylacetylene, phenylethynyl chloride or phenylethynyl iodine to react with 2 a under the standard conditions. Phenylethynyl iodide gave the product $4 \mathbf{a}$ in $82 \%$ yield, while phenylacetylene and phenylethynyl chloride were failed to convert into the product (Scheme 2, eqn (1)). The presence of TEMPO or BHT strongly suppressed the product formation, respectively gave the product $\mathbf{4 a}$ in $0 \%$ and $15 \%$ yields (Scheme 2 , eqn (2)). These results indicated that a radical pathway may be involved. However, we did not detect the additive products of radicals coupling with TEMPO or BHT. When the 4-methylbenzenesulfinic acid 5 reacted with $2 \mathrm{a}$ in absence of $12 \mathrm{M} \mathrm{HCl}$, the product $3 \mathrm{a}$ was obtained in $45 \%$ yield (Scheme 2 , eqn (3)). The vinyl sulfone 6 could not transformed into the product with 2a under standard reaction condition (Scheme 2, eqn (4)). We next investigated whether $\mathbf{4 a}$ was the reaction intermediate for the formation product 3a. Sodium sulfinates could add into $4 \mathbf{a}$ to form $3 \mathrm{a}$ in excellent yield in the presence of $12 \mathrm{M} \mathrm{HCl}$ (Scheme 2, eqn (5)).

According to previous studies ${ }^{\mathbf{1 5 , 1 6}}$ and our control experiments, the proposed mechanisms were shown in Scheme 3. One proposed mechanism was a addition-elimination process (path a). ${ }^{15}$ Firstly, the nucleophilic attack of sulfinate ion to $1 \mathrm{a}$ formed the intermediate $\mathbf{A}$, which was followed by protolysis to give the intermediate B. Finally, the intermediate $\mathbf{B}$ eliminated hydrogen bromide to produce the product 4a. The other mechanism was a radical process (path $\mathrm{b}$ ). The $p$-tolylsulfonyl radical $\mathbf{C}$ could be generated from sodium $p$-tolylsulfinate in acid under heated condition. ${ }^{16 a, b}$ Subsequently, a radical

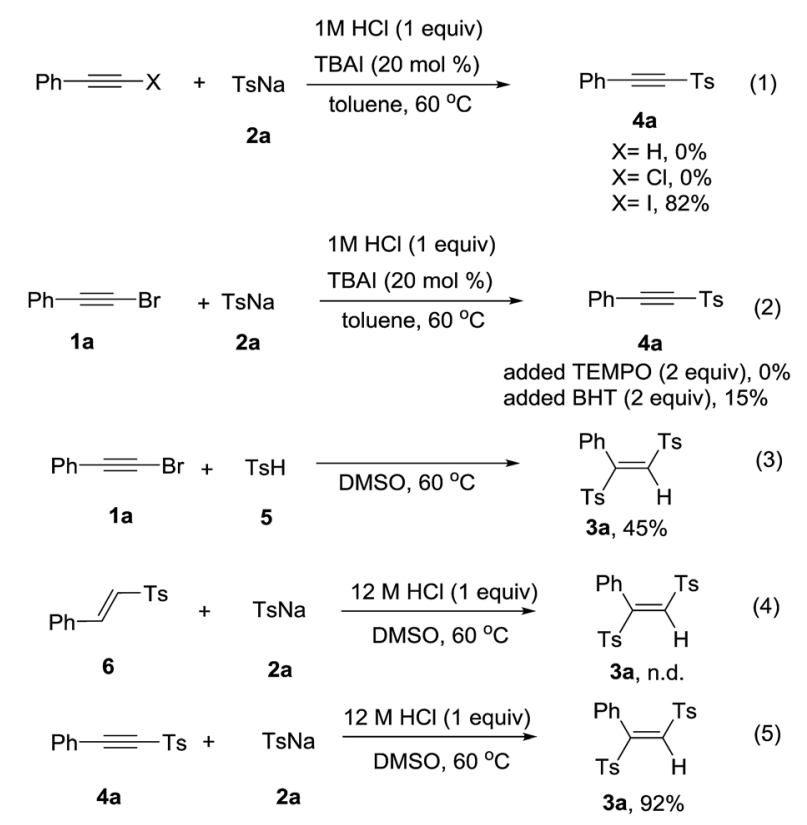

Scheme 2 Control experiments. 

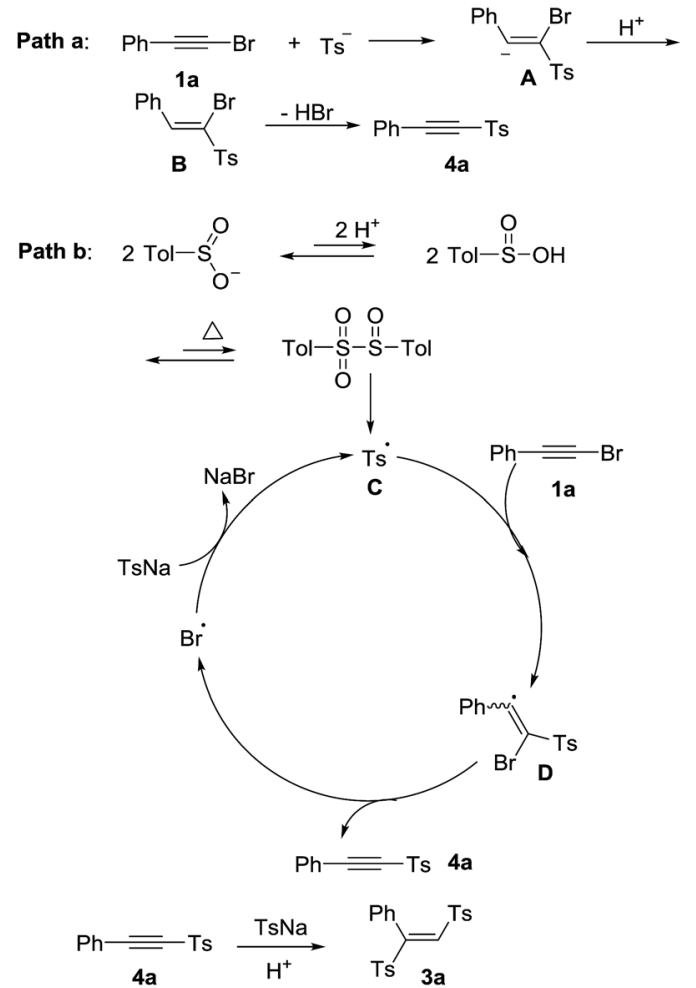

Scheme 3 Possible reaction mechanism.

addition of $p$-tolylsulfonyl radical to 1a formed a bromovinyl radical D. ${ }^{16 c}$ Then, the product $4 \mathrm{a}$ was obtained via bromine radical elimination from $\mathbf{D}^{16 c}$ Finally, the bromine radical oxidized sodium $p$-tolylsulfinate to afford $p$-tolylsulfonyl radical C with releasing $\mathrm{NaBr}^{16 c}$ The $\mathbf{4 a}$ could be transformed into the product 3a through nucleophilic addition. The polarity of the solvent determined the final product was $\mathbf{4 a}$ or $\mathbf{3 a}$. The final product was $4 \mathrm{a}$ in the low polar solvents such as toluene, $\mathrm{CHCl}_{3}$, DCE and so on. The high polar solvent was good for nucleophilic addition process. So when the high polar solvents such as DMSO, DMF, $\mathrm{CH}_{3} \mathrm{CN}$ were used, the final product was $\mathbf{3 a}$.

In conclusion, we have developed a practical and novel procedure for the synthesis of $(E)$-1,2-bis(arylsulfonyl)ethylenes and arylacetylenic sulfones by sulfonylation of arylethynylene bromides with sodium arylsulfinates in different solvents. The method obviated the need for unavailable starting materials or strong oxidants with simple operation. Further research for the mechanism and the synthetic applications are ongoing in our laboratory.

\section{Acknowledgements}

The authors thank the High-level Talent Introduction Foundation of Southern Medical University (C1033520), and the Science and Technology Program of Guangdong Province (2015A010105015) for financial support.

\section{Notes and references}

1 (a) E. Dunny, W. Doherty, P. Evans, J. P. G. Malthouse, D. Nolan and A. J. S. Knox, J. Med. Chem., 2013, 56, 6638; (b) H. Rueeger, R. Lueoend, O. Rogel, J.-M. Rondeau, H. Möbitz, R. Machauer, L. Jacobson, M. Staufenbiel, S. Desrayaud and U. Neumann, J. Med. Chem., 2012, 55, 3364; (c) M. Uttamchandani, K. Liu, R. C. Panicker and S. Q. Yao, Chem. Commun., 2007, 1518; (d) Y. Shen, C. A. Zificsak, J. E. Shea, X. Lao, O. Bollt, X. Li, J. G. Lisko, J. P. Theroff, C. L. Scaife, M. A. Ator, B. A. Ruggeri, B. D. Dorsey and S. K. Kuwada, J. Med. Chem., 2015, 58, 1140. 2 (a) M.-Y. Chang and Y.-C. Cheng, Org. Lett., 2016, 18, 1682; (b) M.-Y. Chang, Y.-C. Cheng and Y.-J. Lu, Org. Lett., 2014, 16, 6252; (c) J.-C. Wu, L.-B. Gong, Y. Xia, R.-J. Song, Y.-X. Xie and J.-H. Li, Angew. Chem., Int. Ed., 2012, 51, 9909. 3 (a) R. Robles-Machín, A. López-Pérez, M. GonzálezEsguevillas, J. Adrio and J. C. Carretero, Chem.-Eur. J., 2010, 16, 9864; (b) Z. Li, H. Yu, H. Liu, L. Zhang, H. Jiang, B. Wang and H. Guo, Chem.-Eur. J., 2014, 20, 1731; (c) E. Conde, I. Rivilla, A. Larumbe and F. P. Cossío, J. Org. Chem., 2015, 80, 11755; (d) J. Mancebo-Aracil, C. Nájera and J. M. Sansano, Org. Biomol. Chem., 2013, 11, 662.

4 (a) V. Corcé, L.-M. Chamoreau, E. Derat, J.-P. Goddard, C. Ollivier and L. Fensterba, Angew. Chem., Int. Ed., 2015, 54, 11414; (b) A.-P. Schaffner, V. Darmency and P. Renaud, Angew. Chem., Int. Ed., 2006, 45, 5847; (c) Y. Amaoka, M. Nagatomo, M. Watanabe, K. Tao, S. Kamijo and M. Inoue, Chem. Sci., 2014, 5, 4339; (d) R. Beniazza, V. Liautard, C. Poittevin, B. Ovadia, S. Mohammed, F. Robert and Y. Landais, Chem.-Eur. J., 2017, 23, 2439; (e) C. Poittevin, V. Liautard, R. Beniazza, F. Robert and Y. Landais, Org. Lett., 2013, 15, 2814.

5 (a) A. Quintard and A. Alexakis, Org. Biomol. Chem., 2011, 9, 1407; (b) A. Quintard and A. Alexakis, Chem.-Eur. J., 2009, 15, 11109; (c) A. Quintard, S. Belot, E. Marchal and A. Alexakis, Eur. J. Org. Chem., 2010, 927.

6 (a) O. D. Lucchi, V. Lucchini, L. Pasquato and G. Modena, J. Org. Chem., 1984, 49, 596; (b) D. B. Reddy, N. C. Babu, V. Padmavathi and R. P. Sumathi, Synthesis, 1999, 491; (c) M. Ochiai, K. Oshima, Y. Masaki, M. Kunishima and S. Tani, Tetrahedron Lett., 1993, 34, 4829; (d) T. Kataoka, Y. Banno, S.-I. Watanabe, T. Iwamura and H. Shimizu, Tetrahedron Lett., 1997, 38, 1809; (e) S.-I. Watanabe, K. Yamamoto, Y. Itagaki and T. Kataoka, J. Chem. Soc., Perkin Trans. 1, 1999, 2053; (f) S.-I. Watanabe, K. Yamamoto, Y. Itagaki, T. Iwamura, T. Iwama, T. Kataoka, G. Tanabe and O. Muraoka, J. Chem. Soc., Perkin Trans. 1, 2001, 239.

7 W. Wu and H. Jiang, Acc. Chem. Res., 2014, 47, 2483.

8 For selected examples: (a) G. Jiang, C. Zhu, J. Li, W. Wu and H. Jiang, Adv. Synth. Catal., 2017, 359, 1208; (b) N. Rajesh and D. Prajapati, RSC Adv., 2014, 4, 32108.

9 (a) N. Matsuyama, K. Hirano, T. Satoh and M. Miura, Org. Lett., 2009, 11, 4156; (b) Y.-J. Liu, Y.-H. Liu, S.-Y. Yan and B.-F. Shi, Chem. Commun., 2015, 51, 6388; (c) J. Li, W. Hu, C. Li, S. Yang, W. Wu and H. Jiang, Org. Chem. Front., 2017, 4, 373; (d) Y. Dong, S. Sun, F. Yang, Y. Zhu, W. Zhu, H. Qiao, Y. Wu and Y. Wu, Org. Chem. Front., 2016, 3, 720.

10 (a) A. Allen, K. Villeneuve, N. Cockburn, E. Fatila, N. Riddell and W. Tam, Eur. J. Org. Chem., 2008, 4178; (b) Y. Gao, 
M. Yin, W. Wu, H. Huang and H. Jiang, Adv. Synth. Catal., 2013, 355, 2263.

11 For selected examples: (a) Y. Gao, W. Wu, Y. Huang, K. Huang and H. Jiang, Org. Chem. Front., 2014, 1, 361; (b) W. Wei, H. Cui, D. Yang, X. Liu, C. He, S. Dai and H. Wang, Org. Chem. Front., 2017, 4, 26; (c) F. Xiao, H. Chen, H. Xie, S. Chen, L. Yang and G.-J. Deng, Org. Lett., 2014, 16, 50; (d) X. Pan, J. Gao, J. Liu, J. Lai, H. Jiang and G. Yuan, Green Chem., 2015, 17, 1400; (e) V. G. Pandya and S. B. Mhaske, Org. Lett., 2014, 16, 3836; (f) S. Liang and G. Manolikakes, Adv. Synth. Catal., 2016, 358, 2371; $(g)$ X. Tang, L. Huang, Y. Xu, J. Yang, W. Wu and H. Jiang, Angew. Chem., Int. Ed., 2014, 53, 4205; (h) J. Shi, X.-D. Tang, Y.-C. Wu, J.-F. Fang, L. Cao, X.-Y. Chen and Z.-Y. Wang, RSC Adv., 2016, 6, 25651.

12 CCDC 1502249 (3a) contains the supplementary crystallographic data for this paper. $\dagger$

13 For selected examples: (a) H. Chen and L. Zhang, Angew. Chem., Int. Ed., 2015, 54, 11775; (b) J. L. G. Ruano, J. Alemán, L. Marzo, C. Alvarado, M. Tortosa, S. DíazTendero and A. Fraile, Chem.-Eur. J., 2012, 18, 8414; (c) L. Marzo, A. Parra, M. Frías, J. Alemán and J. L. G. Ruano,
Eur. J. Org. Chem., 2013, 4405; (d) R. Ren, Z. Wu, Y. Xu and C. Zhu, Angew. Chem., Int. Ed., 2016, 55, 2866; (e) N. Riddell and W. Tam, J. Org. Chem., 2006, 71, 1934.

14 For selected examples: (a) W. E. Truce, H. E. Hill and M. M. Boudakian, J. Am. Chem. Soc., 1956, 78, 2760; (b) J. W. Lee and D. Y. Oh, Synlett, 1990, 290; (c) J. W. Lee, T. H. Kim and D. Y. Oh, Synth. Commun., 1989, 19, 2633; (d) D. J. Hamnett and W. J. Moran, Org. Biomol. Chem., 2014, 12, 4156; (e) J. Meesin, P. Katrun, C. Pareseecharoen, M. Pohmakotr, V. Reutrakul, D. Soorukram and C. Kuhakarn, J. Org. Chem., 2016, 81, 2744; (f) R. Singh, B. K. Allam, N. Singh, K. Kumari, S. K. Singh and K. N. Singh, Org. Lett., 2015, 17, 2656.

15 (a) G. R. Ziegler, C. A. Welch, C. E. Orzech, S. Kikkawa and S. I. Miller, J. Am. Chem. Soc., 1963, 85, 1648; (b) S. I. Miller, C. E. Orzech, C. A. Welch, G. R. Ziegler and J. I. Dickstein, J. Am. Chem. Soc., 1962, 84, 2020.

16 (a) J. L. Kice and N. E. Pawlowski, J. Am. Chem. Soc., 1964, 86, 4898; (b) C.-P. Chuang, Tetrahedron Lett., 1992, 33, 6311; (c) J. Zhang, P. Li and L. Wang, Org. Biomol. Chem., 2014, 12, 2969. 